\title{
5. Safety vs credibility: West Papua Media and the challenge of protecting sources in dangerous places
}

\section{ABSTRACI}

West Papua Media (WPM) is an innovative media outlet established in 2007 in response to the ongoing human rights crisis in the Indonesian provinces that self-identify as West Papua. The context of its establishment included rising hope about the potential of citizen media to empower repressed publics, complaints from mainstream media about the difficulty of establishing the credibility of reports emerging from the provinces, a ban on foreign media, and political moves by Australia to prioritise its relationship with the Indonesian government over demanding an end to oppressive military behaviour in West Papua. This article documents the strategies WPM has pioneered to bolster its credibility and protect its journalists and sources who work and live in an oppressive context. It also contextualises these strategies in relation to standard journalism processes (Lamble, 2004, 2011); current best practice about the protection of journalists in conflict zones (Cramer, 2009); and emerging concepts of global journalism ethics (Ward, 2010).

Keywords: conflict reporting, credibility, human rights, indigenous, international journalism, news agencies, news-gathering, West Papua

KAYT DAVIES

Edith Cowan University, Perth

7 HE YEAR 2011 was a remarkable one that saw shifts in power balances worldwide. Media, both mainstream and social, played a part in snowballing support for change - especially media from deep inside 
protesting crowds. While the political contexts of the crowds gathered in Tunisia, Egypt, Yemen, Libya, China, Burma, London, Wall Street, Jayapura, Melbourne and elsewhere varied enormously, their online connectivity and media production and distribution skills allowed them to share the narrative of struggle through footage of violent oppression and the power of crowd voices, creating a sense of global solidarity and mutual support.

The protesting crowds were prolific in their media content creation, creating challenges for editors faced with the task of assessing the credibility, as well as the relevance and narrative and digital quality, of citizen-generated content. While 2011 presented an influx of this sort of material, the dilemma of how to handle it was not entirely new to newsrooms. The BBC points to 2005 as being the watershed year in the evolution of its relationship with social media (Harrison, 2009) with images of London bombings taken by people near the sites and posted directly to social media forcing a rethink of the relationship between newsrooms and citizen journalists. Since then the BBC has refined its processes for handling user-generated content via a dedicated 'hub' and Australia's $\mathrm{ABC}$ is now following suit with a new research collaboration initiated in early 2012 beginning to explore new ways of working with user-generated content (Public Media Social Knowledge Roundtables, 2012).

It is not only mainstream newsrooms that are adjusting to the new world of social media and the potential impact of locally-produced content, developing protocols to take advantage of the flexibility, immediacy and interactivity of new media. Faced with a desire to end impunity for war criminals and oppressors, and with growing limits on cash-strapped mainstream newsrooms, human rights journalism networks, populated by digital natives, are picking up some of the time-honoured tools of journalism in order to enable fact checking and to improve their credibility.

This paper will describe the evolution of West Papua Media (WPM), an innovative media outlet established in 2007 in response to complaints from mainstream media about the difficulty of establishing the credibility of reports emerging from West Papua ${ }^{1}$, where a foreign media ban has been in place since 2004 (IFJ, 2006). It will document, for the first time in the public domain, the strategies WPM has developed to both bolster its credibility and protect its journalists and sources who work and live in an oppressive context, and it will analyse WPM's practices via comparisons with standard journalism processes (Lamble, 2004, 2011); best practice about protecting journalists in 
conflict zones (Cramer, 2009); and emerging concepts of global journalism ethics (Ward, 2010).

Despite calls by the International Federation of Journalists, and others, for an end to the Indonesian government's ban on entry into West Papua by foreign media, the ban persists, along with a ban on international humanitarian organisations such as the International Committee of the Red Cross, and has provided the context for the emergence of a vibrant network of civil resistance journalists. Updating the status of media freedom in the Pacific, Perrottet and Robie reported in late 2011 that

Jakarta still upholds its prohibition on all foreign journalists and media workers from entering either province in West Papua, unless pre-approved under a slow and bureaucratic process from the Ministry of Information. [And] even after approval, journalists are always accompanied by a minder from the Badan Intelijen Nasional (National Intelligence Body). (p. 178)

According to Nick Chesterfield, founder and editor of West Papua Media, the online news service was initially a collaboration between four fixers, who had been helping foreign journalists get into and around Papua. The foundational concept, discussed by the four in 2007, was that more news would get out if they trained local journalists in credible information gathering techniques and helped them to get their news and footage out, than by shepherding occasional foreigners through the jungles (N. Chesterfield, personal communication, 16 January 2012). This was the year after Dan Gillmor's (2006) book We the Media had sparked widespread debates and some consternation in media companies by arguing that the rise of citizen journalism would improve the media and strengthen democracy.

Describing this brave new world, Gillmor wrote:

Participatory journalism is a healthy trend, however disruptive it may be for those whose roles are changing. Some of the journalism from the edges will make us all distinctly uncomfortable, raising new questions of trust and veracity. We'll need, collectively, to develop new standards of trust and verification; of course, the lawyers will make some of those new rules. And today's dominant media organisations - led by Hollywood-are abusing copyright laws to shut down some of the most useful technologies for this new era, while governments increasingly 
shield their activities from public sight and make rules that effectively decide who's a journalist. (p. vi)

Describing the rise of citizen journalism, the BBC's Richard Sambrook (2009) described four kinds of activity or sharing: Eye witness reporting; sharing opinion; original, investigative reporting; and networked journalism that involves calling on others to share facts and insights that make a story more comprehensive. West Papua Media is focused on the first of these and coined the term 'witness broadcasting' (adapted from eyewitness journalism) to describe the content it produces.

The year 2007 was also the year after Australia signed the Lombok Treaty with Indonesia; an agreement that starts with a reiteration of both nations' commitment to the purposes and principles of the United Nations, but that also clearly states that they are committed to 'non-interference in the internal affairs of one another' (DFAT, 2011). The signing of this treaty by the Howard government in 2006, sparked the flight of a group of political refugees from West Papua by boat to Queensland where they sought asylum (Wainggai, 2012). This event, in turn, prompted John Howard to 'introduce laws into the Commonwealth Parliament that changed the way Australia treated asylum seekers' (Errington, Miragliotta \& Barry, 2010, p. 234).

Chesterfield was one of the four fixers who founded WPM, and the only Australian among them. Asked for the names of the other members of the network, he said: 'I can tell you off the record, but their names can't be published because it would prevent them from being able to go back into Papua. And if they have been there already, then the people they are known to have stayed with and associated with would be arrested' (Personal communication, 2 February 2012). Responses like this frustrate journalists and academics who like to name sources and to identify their subjects, but illustrate WPM's need and commitment to source protection.

Elaborating on the drivers behind the establishment of WPM, Chesterfield said:

When activists were trying to get West Papua into the media there were always complaints from mainstream journos that the information wasn't credible and certainly there have been some cases of stories where claims couldn't be verified. And there were very, very powerful voices 
that were rubbishing all of the claims that came out of West Papua. So from a human rights data perspective we were looking at a situation where the best way to ensure high quality factual reportage coming out of Papua was to make sure there was some sort of basic training and methodologies were agreed upon by local people. And in reality as well, the more we, as media fixers, were seeking to organise and get factual stories out of Papua, the more we realised that we were doing the work of journalism and journalism training. (Personal communication, 16 January 2012).

\section{Recruitment and training}

In 2007, with help and advice from some of the journalists they had worked with, they started an email news group, that saw them sending out news articles that they had written to a list of journalists they knew through their fixing work. This was just a rough beginning though, as their aim was to create a network of stringers whose accuracy they (and other editors) could trust. In order to achieve this, they set about adapting the field-research methodology used by the leading human rights organisations. These forms and protocols are derived from ethnographic techniques and incorporate quantitative data gathering, such as body counts with tables and tallies. The adaptations were designed to yield the sort of information that journalists and newsrooms need to construct simple straight-forward hard news articles, and to build an archive of documentation to enable basic fact checking and the cross-checking of facts. This was to suit not only the journalistic preferences for verifiable facts, but also to answer critiques of the human rights data gathering methodologies, that have been accused of being too subjective to allow accurate international comparisons (Barsh, 1993).

While the WPM founders were not reading academic debates about human rights methodologies at the time, they had observed the problems Barsh (1993) raised, that included difficulties with non-uniform definitions of value-laden terms such as 'freedom'. The WPM approach was also in line with Gillmor's (2006) call for collectively developed new standards of verification in citizen journalism. Chesterfield said that as all four fixers had previously worked for human rights organisations, between them they had a range of experiences of working with these protocols and methodologies. Their adapted methodology includes the classic question set 'Who, What, Where, When, Why and How'. Lamble (2004 \& 2010) described this question set as being sufficiently core 
to journalism practice that it can be used as one of the features that identifies journalism as a distinct research methodology. Other defining characteristics of journalism, according to Lamble (2004) include a preference for empirical data, a neutral point of view approach to reporting, and a combination of deliberate and network sampling to recruit subjects for interview. The WPM protocol incorporates all of these features. It also encourages the use of tables for recording the names, ages, addresses, injuries, and other specific details about people involved in violent incidents and a layer of protocol about recording when and where photos were taken and how information should be transmitted and archived. Once this protocol had been established, they started recruiting Papuans in Papua to become their network of stringers (N. Chesterfield, personal communication, 16 January 2012).

The first recruits were 10 people they already knew and trusted, who, in addition to going through their training and passing an assessment on the use of the new methodology, also gave them what Chesterfield called 'a laundry list of all of the sorts of things that they needed access to and training for'. The list included basic journalism training, as well as cameras, audio recorders, laptops, mobile phones, and skills in how to secure, disseminate and back up their material. He said WPM was still working through this list and seeking funding to extend its training and acquire more hardware and bandwidth. Since 2008, West Papua Media has trained more than 30 stringers, expanding the reach of its network through the troubled territory. The training has taken the form of one-on-one and small group work, the development and use of training materials, scenario-based workshops, and assessments to ensure comprehension, retention and proficiency (N. Chesterfield, personal communication, 16 January 2012).

West Papua Media now has a website (westpapuamedia.info) that garnered 182,372 direct page views in 2011. It has 143 subscribers to the website's news feed and an additional 104 journalists on a media-only list. It also sends out links to content to 536 Facebook followers and 1500 Twitter followers, with potential for these posts to reach 1.6 million people, (according to the metrics offered by Facebook on the back end of the West Papua Media Alerts Facebook page on 2 February 2012). West Papua Media content is also distributed by several other e-lists reaching a combined total 30,000 to 40,000 , through content sharing arrangements. In addition, content is mirrored on other sites including Pacific Scoop and Scoop New Zealand, Pacific Media 
Centre Online, AK Rockefeller and a host of other civil resistance and media sites, some of which also publish the WPM Twitter feed. WPM also continues to liaise with media companies, offering both fixing services and access to text, images, audio and footage when big news breaks or investigative pieces are completed. WPM is funded by donations from individuals. No one is paid a salary or fees for providing content, training or consulting. When media companies pay for content or services, that revenue goes to the individual or team that produced that content, but they usually chose to donate the money back to WPM to help cover operating costs such as broadband and phone bills. (N. Chesterfield, personal communication, 8 February 2012).

While the project has had some success in getting news onto Australian front pages and TV screens, Chesterfield believes the behaviour of Indonesian security forces in West Papua is still under-reported in Australia, given that Australia's support of the Indonesian regime and the involvement of Australian mining companies gives a Fourth Estate rationale for covering it. Asked for his take on why it is not covered more, he said: 'If they start covering it now, people will ask why they didn't cover it before.' Another stumbling block is that editors tend to want their own staff to do the eye-witness reporting, but getting into Papua is difficult and requires the help of fixers, who, as part of West Papua Media, make stringent demands about the protection of sources, including limiting the carriage and use of mobile phones that can be triangulated and tracked, and in some cases disguising or not revealing the identities of sources they speak to. According to Chesterfield, the West Papua Media source protection conditions sometimes evoke responses such as 'Oh! We can't take those sorts of precautions, you know it's all about openness and accountability', to which he responds: 'Yeah, but you're going to get people killed' (N. Chesterfield, personal communication, 16 January 2012).

\section{'The most dangerous place'}

WPM's concern for the safety of its workers is not without basis. The provinces topped the Pacific Media Freedom 2011 Report's list, as the most dangerous place for journalists to work in the Pacific region, with two killings, five abductions and 18 assaults in the year to October 2011 (Perrottet \& Robie, 2011). This high level of risk prompted Chesterfield to develop WPM's Safe Witness Broadcasting Training materials and associated scenario-based training modules. Asked if, in his view, this training is more comprehensive than the training most journalists get, he said: 
Completely, yes. One of the things that we've noticed over the years working directly for international media and fixing for international media going into Papua is that they do very, very expensive Hostile Environment First Aid Training (HEFAT) training but they are totally unaware of their source safety and that they'll use iPhones quite happily and not think for a moment that the phone might be tapped or anything like that. There is no experience or training in working under civil resistance and repressive contexts. This is a huge problem because their sources get threatened and we are just really surprised still when we get approached by a lot of journalists who don't take it into account and ask what are the risks going to be for the local people. Some do though and there's certainly more of an understanding now that people talking to journalists can get harmed, certainly more than there was three years ago or four years ago. (N. Chesterfield, personal communication, 16 January 2012).

According to former managing editor of $\mathrm{CNN}$ and head of BBC newsgathering Chris Cramer (2009), a lot of work has been done over the past 20 years to raise the profile of safety and safety awareness in the media industry. This has included industry debates about whether journalists should wear protective clothing such as flak jackets and helmets, whether being clearly labeled as media workers increases or decreases the likelihood of being targeted and the extent to which staff need to be trained and debriefed to minimize shock and trauma, and associated erratic and unhealthy behaviour. According to Cramer, major media rethinks about the safety of journalism in hostile environments were prompted by legislative changes about workplace risks in the UK in the 1990s that prompted the BBC to insist that its journalists undergo training before being deployed to potentially dangerous locations. According to di Giovanni (2009), however, these courses, such as the one run by Centurion in Hertfordshire that she attended in 2003, were of limited use and included advice that if taken literally, could endanger journalists in the field.

While facts and figures about journalists being at risk and placing sources at risk, along with advice from the DART Centre for Journalism and Trauma, are included in many Australian university journalism courses, scenario-based hostile environment training is rare, if it happens at all. Chesterfield confirmed this, from his experience as a fixer and media consultant, saying:

There is an academic awareness that Indonesian security forces will kill journalists and anyone speaking to journalists, and that's always been 
the way. With Balibo, the film, it's certainly come back into people's consciousness, and that's fantastic. But we've got a long way to go with mainstream Australian media, if they want to cover it at all, and quite often the conditions of safety are an excuse for many mainstream Australian media people to refuse to cover it ... it's always very frustrating because there's quite a lot of enquiry but when you tell people they've got to be careful and they've got to give a shit about the lives of their sources, it comes apart. A lot of people baulk at how stringent our conditions are, and don't get back to us, and quite frankly, if they don't understand the need for safe journalism practices, we don't want to work with them anyway - we owe that to our crew. (N. Chesterfield, Personal communication, 16 January 2012).

\section{'No story is worth a life'}

According to Cramer (2009) many news organisations have now adopted the adage that 'no story is worth a life', and that assessment of risk needs to be handled cautiously and respectfully by in-the-field journalists and their newsroom-based colleagues. This resonates with Stephen Ward's (2010) deliberations about journalism ethics. Ward writes that journalism, like 'almost every profession, and every ethical and legal system, makes the avoidance of unjustifiable harm a basic obligation' (p. 164), but he adds that in journalism as in medicine, harm is unavoidable. He compares amputating a leg to save a life with publishing reports on corrupt officials, that does public good but damages the official's prosperity. Discussing the ethical foundations of journalism, he argues that as a profession journalism has an obligation to publicise the plight of oppressed minorities, to promote global human rights standards and to encourage cosmopolitan attitudes as these are in humanity's interests, in terms of long term sustainability. These are all aligned with the aims of WPM, as stated on its website, and practices, as evidenced by the issues it covers.

An additional imperative driving WPM's desire for funding to enable more training is that three things have been running in parallel with the development of the West Papua Media project. These are the growth, in numbers and vitality, of both the non-violent independence and the armed-resistance movements in West Papua, and the rapid uptake of new technologies by West Papuans in both urban and remote locations. This expansion of activity has meant there are more opportunities for citizens to take risks in order to capture video of news events unfolding, and in turn more opportunities for that video to be 
rendered useless because of slow transmission to newsrooms or incomplete documentation about when and where it was filmed. Chesterfield worries that people trying to film events involving live ammunition and repressive conduct by armed forces, without basic training in how to stay safe while doing that, are risking their lives. In his words:

In Papua, anyone with a camera will take a photo if they see something happening and this is why we want to expand, because it's extremely dangerous. We want anyone who wants to hold up a camera to be a journalist and we want them to be a safe journalist. There are ways, for instance, in a situation with live fire to ensure that footage is taken without putting yourself or your friends in harm's way. (N. Chesterfield, personal communication, 16 January 2012).

WPM's Safe Witness Broadcasting Training is extrapolated from HEFAT that some of the West Papua Media crew were familiar with, having previously worked for human rights monitoring organisations. They extended and customised the training to include journalism scenarios, requiring news judgment and level-headedness in the face of threats to personal safety. Its key difference, however, to HEFAT (which deals with obvious war situations), is that it deals with complex civil resistance scenarios both before and after violence, and assumes no organisational back-up, evacuation or mercenaries on hand. If funding allows, West Papua Media plans to do more training in and around West Papua in 2012, but funding is a sticking point as the project relies entirely on donations from individuals and all-too-rare payments from media companies for the content they use.

\section{'Separatism', fairness and balance}

One of the concerns some news editors have raised about using WPM content is that the news service appears to be 'pro-separatism', and therefore not fair and balanced in its reporting. Chesterfield counters that compared with other sources of news, such as agencies (that newsrooms have easy pre-paid access to) WPM is less biased because it has eyewitness reporters in-country and they don't privilege news from official PR sources that apply spin and gloss. He also noted the newsroom truism 'if it bleeds it leads' and added 'but how do you prove it's bleeding unless you see red.' This motivates the push to incorporate photography and video into the WPM outputs, but he 
pointed to risks involved in immediate transmission of images in some cases, for journalists and their sources, because they can be geo-located when they use phones as modems for sending digital content. He said delays in getting images can make a story seem stale and less interesting to newsrooms. Expanding on these points he said:

Unlike media agencies, we actually bother to go after the witnesses and we find who the witnesses are, or we get human rights workers to go and interview the witnesses. We believe that human rights reporters in Papua are legitimate sources of information because they have been through a testing and vetting process, they've got a systematic process of gathering information and they can present raw data if required. But their data is very, very strongly labeled in our articles: this fact, that fact, that fact and that fact. You can't argue with a table of victim data. These are the hard difficult sources and lengths that we've got to go through. We'll much more trust a church person who's gone through a strong process of a systematic report that's done, showing all the data, than we will believe whatever the Indonesian government or security forces public affairs person said. Whereas a lot of the mainstream media, their first thing is to ring up the Indonesian military and say: 'Did you go and kill so and so? Or did you go and burn down 100 villages?' And of course they are going to say that they didn't, and the problem with the mainstream media, when it comes to Indonesia, with a few very, very honorable exceptions, is that they rely too much on official sources because it's too hard to get to your local sources. And THAT is our big difference. We have the talent on the ground. (N. Chesterfield, personal communication, 16 January 2012).

While asserting its commitment to empiricism and factual accuracy, WPM also proudly identifies itself on its website as 'civil resistance media'. Chesterfield explains that WPM's coverage of human rights abuses in West Papua is part of what West Papua activists and civil resistance activists around the world, following the strategies outlined by Sharp (2005), call the 'push, pull and squeeze' strategy. The process is as follows: Indigenous resistance, through civil mass resistance, either civil or armed, in an occupied territory, will push out the occupiers, if, at the same time there is a pull provided by the withdrawal of moral consent by the population of the occupying power, which can be activated and documented via media coverage in the nation state involved. The squeeze, that also helps the process, comes 
from international embarrassment and pressure activated through coverage of the abuses and oppression in foreign media. He says that while WPM is not pro-separatist it is explicitly anti-violation of human rights. (N. Chesterfield, personal communication, 16 January 2012).

While this is not a neutral position, it is in accord with what Ward (2010) argues are some of the ultimate aims of modern journalism over its 400 year history. He summarises these aims that journalism organisations and scholars have espoused as: 'To report and disseminate information; to interpret events and trends; to act as a watchdog; to advocate for reform or revolution; to be an activist for certain causes; to educate the public and guide public opinion; and to service the public, the party or the state' (p. 73). Ward goes on to argue that it is becoming harder for journalism to ethically justify serving parties and states, and that promotion of global justice is a safer and more sustainable aim for all media to aspire to. He acknowledges that there are competing interests pulling the strings behind media agendas but urges reflective practice among journalists in order to challenge newsroom practices that diminish awareness of global perspectives.

\section{Conclusion}

In conclusion, this article has profiled an innovative news service that is pioneering the development of citizen journalism, online and viral dissemination, media and source safety in hostile and oppression contexts and in ethical global-journalism practice. While West Papua is still a troubled province with 29 churches and 13 villages in the Paniai area burnt down in the past few months (Wainggai, 2012) and harsh sentences recently imposed on the pro-independence leaders arrested in October 2011, the Indonesian government and security forces know that their ban is not able to keep the eyes of the world out and this means that WPM is functioning as a watchdog over the troubled territory. 


\section{Note}

1. West Papua (also known as Western New Guinea) has been adopted by Pacific Journalism Review to refer collectively to the territory covering the western peninsula of the Pacific island of New Guinea where the issue of Melanesian independence or self-determination is critical. Indonesia has administered the territory as two provinces since 2003-West Papua and Papua. A former colony as part of the Netherlands East Indies, Indonesia attempted to seize control with a seaborne and paratrooper invasion in 1963 with little success. However, it succeeded in incorporating the territory as part of Indonesia in the United Nations mandated so-called 'Act of Free Choice' in 1969 that has been disputed ever since by many Melanesian West Papuans.

\section{References}

Barsh, R. L. (1993). Measuring human rights: Problems of methodology and purpose. Human Rights Quartlerly, 15(1), pp. 87-121.

Cramer. C. (2009). Taking the right risk. In Owen, J., \& Purdey, H. (Eds.), International news reporting: Frontlines and deadlines (pp. 163-190). London: Wiley-Blackwell.

Department of Foreign Affairs and Trade (2006). Agreement between the Republic of Indonesia and Australia on the framework for security cooperation. Retrieved on 8 February 2011, from: www.dfat.gov.au/geo/indonesia/ind-aus-sec06.html

Di Giovanni, J. (2009). Bearing witness. In Owen, J., \& Purdey, H. (Eds.), International news reporting: Frontlines and deadlines (pp. 1-14). London: Wiley-Blackwell.

Errington, W., Miragliotta, N., \& Barry, N. (2010). Australian political systems in action. Melbourne: Oxford University Press.

Gillmor, D. (2006). We the media. Retrieved on 8 February 2012, from: www.hypergene.net/wemedia/download/we_media.pdf

Harrison, J. (2009). User-generated content and gatekeeping at the BBC hub. Journalism Studies, 11(2), pp. 243-256.

International Federation of Journalists. (2006, February 17). IFJ says foreign media ban in West Papua continues to obstruct press freedom. Retrieved on 12 February 2012, from: www.ifj.org/en/articles/ifj-says-foreign-media-ban-in-west-papuacontinues-to-obstruct-press-freedom-

Lamble, S. (2004). Documenting the methodology of journalism. Australian Journalism Review, 26(1), pp. 85-106.

Lamble, S. (2011). News as it happens: An introduction to journalism. Melbourne: Oxford University Press.

Perrottet, A., \& Robie, D. (2011). Pacific media freedom 2011: A status report. Pacific Journalism Review, 17(2), pp. 148-156. Retrieved on 12 February 2012, from www. pjreview.info/articles/special-report-pacific-media-freedom-2011-status-report-513

Public Media Social Knowledge Roundtables. (2012). Retrieved 14 March 2012 from: http://publicmediasocialknowledge.wordpress.com/

Sambrook, R. (2009). Citizen journalism. In Owen, J., \& Purdey, H. (Eds.), 
International news reporting: Frontlines and deadlines (pp. 220-242). London: Wiley-Blackwell.

Sharp, G. (2005). From dictatorship to democracy: A conceptual framework for liberation. Boston: Albert Einstein Institution.

Wainggai, H. (2012). Press statement by the Federated Republic of West Papua, 17 January 2012. Retrieved on 8 February 2012, from: http://hermanwainggai. blogspot.com.au/2012/01/press-statement-federated-republic-of.html

Ward, S. (2010). Global journalism ethics. Montreal: McGill-Queens University Press.

Dr Kayt Davies is a senior lecturer in journalism at Edith Cowan University. She has worked for The West Australian, Visviews, (London) and edited community newspapers and magazines. Her doctorate was an ethnographic study of women's magazine editors.

k.davies@ecu.edu.au

The Journalism, Media and Democracy Research Centre invites papers for a one-day conference entitled:

\section{AUSTRALIAN AND NEW ZEALAND MEDIA HISTORIES COMMONALITY, AUTONOMY, CONVERGENCE}

Keynote speaker: Professor Peter Putnis, University of Canberra

\section{AUT University, Auckland, NZ I September 13, 2012}

A s settler societies, Australia and New Zealand experienced similar early histories in the

Acommuncations field. Today, after a period of separate development, during which Aboriginal and Maori activist media openly challenged colonialist versions of history, the commonalities and differences of our media inhabit a global environment. With these thoughts in mind researchers are invited to submit papers in response to the following themes:

- Media organisations and news journalism

- Journalism, war and conflict

- Maori and Aboriginal media

- Political economies of media

- Australian and NZ media in Asia-Pacific

- Media representations of national identities

- Telecommunications

- Media and popular culture

\section{Abstracts due: June 30}

Send abstracts to Associate Professor Wayne Hope (wayne.hope@aut.ac.nz or jmad@aut.ac.nz). For further information contact Greg Treadwell (gregory.treadwell@aut.ac.nz).

Registration: NZ\$150 (Earlybird before June 30 \$110; student concession \$60) 